\title{
Characteristics of Insulin and Androgen Status in Polycystic Ovary Syndrome
}

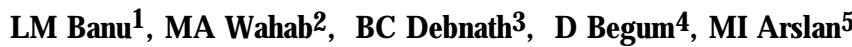 \\ 1D ept of Biochemistry, East West Medical College, Dhaka, \\ 2Dept of Biochemistry, Armed Forces Medical College, Dhaka, \\ 3D ept of Biochemistry, MAG O smani Medical College, Sylhet, \\ ${ }^{4}$ Central Police Hospital, D haka, \\ 5D ept of Biochemistry, Bangabandhu Sheikh M ujib Medical U niversity, Dhaka
}

\begin{abstract}
Polycystic Ovary Syndrome (PCOS) was originally described as a syndrome of amenorrhea, hirsutism and obesity associated with enlarged polycystic ovaries. There is increased androgen level and in some, insulin resistance (IR). Etiological relationship of androgen excess and IR in PCOS is not established. Influence of obesity on PCOS is controversial. This study was designed to see the androgen and insulin status in PCOS among obese and non-obese patients. It was a case-control study. Of total 80 study subjects, 60 primary infertile women suffering from PCOS were cases (30 obese and 30 non-obese). A ge and BMI matched 20 healthy women having normal menstrual cycles were controls (10 obese and 10 non-obese). A ge range of all were 20-40 years. Fasting plasma glucose, fasting S. Insulin and free Testosterone were measured. Insul in resistance (IR) was assessed by fasting glucose to insulin ratio $(<4.5)$. Subjects with DM or known endocrine disorders that may be associated with abnormal S.Insulin or plasma glucose concentration were excluded. No significant difference of fasting plasma glucose between PCOS (obese or non-obese) and respective controls ( $P>0.5$, in each) were observed. Significant difference of fasting $\mathrm{S}$. Insulin and testosterone were observed between PCOS (both obese and non-obese) and respective controls $(\mathrm{P}<0.01$ in each), but there was no significant difference between obese and non-obese PCOS $(P>0.05)$. There was no significant difference of $S$.Testosterone between obese and non-obese $P \operatorname{COS}(P>0.05)$. There was also no significant difference of IR between obese and non-obese PCOS, but the ratio was $<4.5$ (indicating IR in both). There were no significant correlation of S.Insulin with Testosterone in any group of PCOS (obese and non-obese) ( $P>0.05)$. Increased S.Insulin and Testosterone was seen in PCOS irrespective of BMI. Further studies with larger sample size is recommended to assess etiological relationship between insulin and testosterone in PCOS.
\end{abstract}

Key Words: PCOS (Polycystic Ovary Syndrome), S. Insulin, S. Testosterone, IR (Insulin Resisfance), Obesity

\section{Introduction}

According to National Institute of Health (1990), 3 minimal criteria for diagnosis of PCOS among women of reproductive age are a)menstrual irregularity, b)biochemical or clinical evidence of hyperandrogenism (Biochemical-elevated androgen level, Clinical- hirsutism, acne or male pattern balding) and c) exclusion of hyperprolactinemia, nonclassical adrenal hyperplasia and thyroid disorders ${ }^{1}$. Burghen et al (1980) reported both basal and glucose stimulated hyperinulinemia in women with $P \operatorname{COS}^{2}$. M any investigators found hyperinsulinemia and hyperandrogenemia are co-existent in $\mathrm{PCOS}^{3}$. 
Peripubertal onset of anovulation manifested as menstrual irregularities (amenorrhea, disfunction uterine bleeding), is a characteristic feature of PCOS(Pasquali et al 1989) 4 .

According to ASRM/ESHRE (2003), PCOS is diagnosed if any two of three criteria present-1. Oligo/anovulation, 2. hyperandrogenism, (clinical or biochemical), 3. polycystic ovaries. Incidence of PCOS is $(0.5-4 \%)$, more common amongst infertile and prevalent in young women of reproductive age ${ }^{5}$.

$50-90 \%$ of women with PCOS have elevated androgen levels, mainly testosterone, androstenedione, DHEA and DHEAS. There is individual variation and some may have normal androgen level ${ }^{6}$. A mong endogenous androgens, testosterone is the most potent, biological activity of which is determined by amount binding to SHBG (sex hormone binding globulin). Only free testosterone is biologically active. Insulin and androgens decrease the hepatic synthesis of SHBG thus increasing the level of free testosterone ${ }^{7}$. Positive correlation was found between serum insulin and adrenal androgens using selective catheterization of ovarian and adrenal veins ${ }^{8}$. Androgens may produce mild insulin resistance ${ }^{3}$. Studies in which insulin levels have been lowered with agents that either decrease insulin secretion (diazoxide, somatostatin), or improve insulin sensitivity (metformin, troglitazone) demonstrate decreased androgen levels as well as $P \operatorname{COS}^{9,10,11}$. Significant association was found between IR and obesity. IR was also found in non-obese PCOS2,12,13. We compared insulin and androgen levels in both obese and nonobese PCOS with controls in our population.

\section{Materials and methods}

It was a case control study, carried out in Biochemistry department of BSMMU, from January 2004 to December 2004.Informed written consent was taken from study subjects. There were 80 study subjects, of 20-40 years age groups. Sixty (60) primary infertile women with PCOS (20 obese, BMI> $25 \mathrm{~kg} / \mathrm{m}^{2}$ and 20 non-obese, $B M I<25 \mathrm{~kg} / \mathrm{m}^{2}$ ) were cases. A ge and BMI matched 20 subjects were controls.
LM Banu, BC Debnath, D Begum, et al.

PCOS was diagnosed according to following criteria: 1) oligomenorrhea or DUB, 2) characteristic USG findings of polycystic ovaries, 3) features of hyperandrogenism, hirsutism, acne etc.

Subjects with bilateral tubal blockage, steroid therapy, known endocrine disorders, chronic illness (Tuberculosis, Malignancy, Connective tissue disorder), renal and hepatic diseases were excluded from the study. Data were collected through a preformed data collection sheet. With all aseptic precaution $5 \mathrm{ml}$ of venous blood was taken from each subject $(2 \mathrm{ml}$ in fluoride containing test tubes for plasma glucose and 3 $\mathrm{ml}$ in plain test tubes). Serum was separated for insulin and testosterone estimation and stored in refrigerator at $-35^{\circ} \mathrm{C}$ till assay done. Fasting plasma glucose was estimated by glucose oxidase method ${ }^{14}$, S. insulin by Abbott AxSym system on MEIA principle ${ }^{15}, S$. free testosterone by ELISA ${ }^{16}$. Insulin resistance (IR) was calculated by using the formula: (fastng glucose: fasting insulin ratio), with a value $<4.5$ taken as a measure of IR ${ }^{17}$. All statistical analyses were done by SPSS, version 12.0. Results were expressed as mean $\pm S D$ or median where applicable. Student's ' $t$ ' test, MannWhitney $U$ test, Spearman's correlation tests were done. $A$ ' $P$ ' value $<0.05$ was considered as statistically significant.

\section{Results}

Distribution of age and BMI is shown in table-l. Unpaired ' $t$ ' test showed no significant difference of age and BMI between cases and controls. In table-II, it was found that there was no significant difference of fasting plasma glucose, between cases and controls as well as between obese and non-obese PCOS(cases). Fasting $S$. Insulin and testosterone were significantly raised in both obese and non-obese PCOS cases but no significant difference was found between obese and non-obese cases (Table-III \&IV). In table-V, Glucose/Insulin ratio (a measure of IR) is presented. There was $I R$ in both obese and non-obese PCOS but no significant difference was observed between obese and non-obese PCOS. There was no correlation of fasting $S$. Insulin with 
Insulin and A ndrogen Status in PCOS

Testosterone and between $\mathrm{S}$. Testosterone \& P. Glucose (Table-VI)

Table I: Distribution of age and BMI in study subjects

\begin{tabular}{|c|c|c|c|}
\hline Group A ge & $p$ & BMI & $P$ \\
\hline \multicolumn{4}{|l|}{ Obese } \\
\hline PCOS $(n=30) 28.23$ & $\pm 3.24>0.05$ & 28.40 & $\pm 2.65>0.05$ \\
\hline Controls $(n=10) 28.40$ & \pm 1.71 & 26.99 & \pm 1.38 \\
\hline \multicolumn{4}{|l|}{ Non obese } \\
\hline $\operatorname{PCOS} \quad(n=30) 26.70$ & $\pm 3.94>0.05$ & 22.79 & $\pm 1.74>0.05$ \\
\hline Controls $(n=10) 28.60$ & \pm 1.43 & .81 & \pm 1.52 \\
\hline
\end{tabular}

Table II: F asting Plasma Glucose in study subjects

\begin{tabular}{lll}
\hline $\begin{array}{l}\text { Groups P.Glucose }(\mathrm{mmol} / \mathrm{L}) \\
\text { (M ean }\end{array}$ & \pm SD ) & \\
\hline $\begin{array}{ll}\text { Obese } \\
\text { PCOS }(n=30) 4.88\end{array}$ & \pm 0.920 .817 & $>0.05$ \\
Controls $(n=10) 5.03$ & \pm 0.28 & \\
Non-obese & & $>0.05$ \\
PCOS $(n=30) 5.14$ & \pm 1.010 .143 & \\
Controls $(n=10) 5.19$ & \pm 0.29 & $>0.05$ \\
PCOS $($ Cases $)$ & & \\
Obese $(n=30) 4.88$ & \pm 0.921 .076 & \\
Non-obese $(n=30) 5.14$ & \pm 1.01 & \\
\hline
\end{tabular}

Table III: F asting S. Insulin level in study subjects

\begin{tabular}{|c|c|c|}
\hline \multicolumn{3}{|c|}{$\mu \mathrm{U} / \mathrm{mL}, \mathrm{M}$ edian(range) 'U' value } \\
\hline $\begin{array}{l}\text { Obese } \\
P C O S(n=30) 21.90(10.20-82.60) \\
\text { Controls }(n=10) 7.30(4.90-13.10)\end{array}$ & 7.0 & $<0.01$ \\
\hline $\begin{array}{l}\text { Non-obese } \\
\text { PCOS }(n=30) 15.65(4.50-21.1) \\
\text { Controls }(n=10) 6.20(4.0-10.40)\end{array}$ & 19.0 & $<0.01$ \\
\hline $\begin{array}{l}P \operatorname{PCOS}(\text { Cases }) \\
\text { Obese }(n=30) 21.90(10.20-82.60) \\
\text { Non-obese }(n=30) 15.65(4.50-21.1)\end{array}$ & 344.0 & $>0.05$ \\
\hline
\end{tabular}

Table IV: S. F ree Testosterone in study subjects

\begin{tabular}{|c|c|c|}
\hline $\begin{array}{l}\text { Groups S. Free } \\
\text { Testosterone } \\
\mathrm{pg} / \mathrm{mL} \text { (M ean }\end{array}$ & $\begin{array}{l}\mathrm{t}^{\prime} \text { value } \\
\quad \pm \mathrm{SD})\end{array}$ & ' $P$ value \\
\hline \multicolumn{2}{|c|}{$\begin{array}{l}\text { Obese } P \operatorname{COS}(n=30) 3.64 \pm 2.145 .12 \\
\text { Controls }(n=10) 0.14 \quad \pm 0.03\end{array}$} & $<0.01$ \\
\hline \multicolumn{2}{|c|}{$\begin{array}{l}\text { Non-obese PCOS }(n=30) 3.86 \\
<0.01\end{array}$} & \pm 2.717 .54 \\
\hline \multicolumn{2}{|c|}{$\begin{array}{l}\text { Controls }(n=10) 0.12 \quad \pm 0.03 \\
\text { PCOS Obese }(n=30) \\
\text { (Cases) }\end{array}$} & $>0.05$ \\
\hline Non-obese $(n=30) 3.86$ & \pm 2.71 & \\
\hline
\end{tabular}

Table V: (Glucose: Insulin) ratio in obese $\&$ non-obese PCOS

\begin{tabular}{|c|c|}
\hline $\begin{array}{l}\text { Groups G/I ratio, M edian(range) } \\
\text { 'U 'value P-value }\end{array}$ & $M-W$ \\
\hline Obese $\quad(n=30) \quad 0.246(0.063-0.490)$ & $1.74>0.05$ \\
\hline N on-obese $(n=30) 0.342(0.025-0.978)$ & \\
\hline
\end{tabular}

Table VI: Spearman's C orrelation of S.Insulin, P. Glucose \& S. Free Testosterone between obese and nonobese PCOS

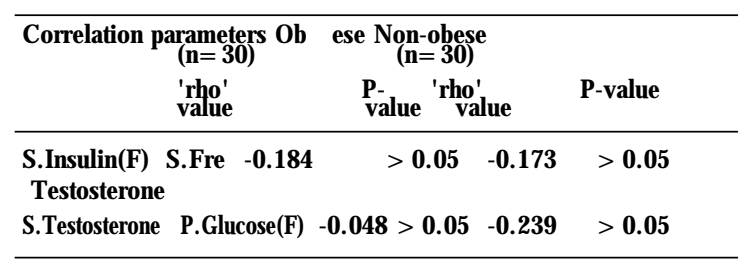

\section{Discussion}

PCOS is a metabolic syndrome with chronic anovulation, hyperandrogenism and polycystic ovaries, with or without obesity. Hyperinsulinemia/IR may be the primary feature of PCOS but some researchers proposed hyperandrogenism as the key featurel. The co-existence of hyperinsulinemia and hyperandrogenism was suggested by some investigators ${ }^{2,18}$.

Fasting P.Glucose was not significantly different between obese and non-obese PCOS and also between PCOS (both obese \&non-obese) and respective controls. This finding was consistent with similar study ${ }^{11}$.

There was significant difference of S.Insulin between PCOS (both obese \&non-obese) and controls. But there was no significant difference between obese and non-obese PCOS, which was consistent with other studies $15,19,2,18$. It is reflective of hyperinsulinemia as a feature of PCOS independent of obesity.

Serum testosterone was significantly increased in PCOS (both obese $\&$ non-obese) than controls. But there was no significant difference between obese and non-obese PCOS, like other studies ${ }^{2,18}$. This might be related to the fact that PCOS is hyperandrogenic independent of body weight.

Fasting Glucose to Insulin ratio $<4.5$, is a predictor of IR in PCOS (in both obese and 
non-obese) ${ }^{19,16}$. In this context, both obese and non-obese PCOS in our study, are insulin resistant. Obese PCOS were more resistant than non-obese group, but there was no significant difference of IR between obese and non-obese PCOS. So, irrespective of body weight PCOS patients are hyperinsulinemic which is due to insulin resistance, like other studies 20,11 .

Although we found hyperinsulinemia and hyperandrogenism in PCOS, we didn't find significant correlation between insulin and androgen levels in PCOS (obese or non-obese).

Most researchers found a positive correlation between hyperinsulinema and hyperandrogenism. But some failed to find such a relationship21,17,22. Hyperandrogenism and polycystic ovaries are commonly found in extreme IR ${ }^{23,3}$. On occasions, both a stimulatory response and lack of it has been observed in the same study. There was a rise of $\mathrm{S}$ testosterone during OGTT in a subgroup of PCOS patients, but most patients showed a decline of $S$. testosterone with both hyperinsulinemia and $\mathrm{LH}$ levels ${ }^{24}$. The effects of insulin on ovulation are complex. Though there is no convincing direct evidence, there are some indirect evidences for the effect of insulin on ovarian steriodogenesis, derived from experiments in a reduction of circulating insulin levels producing a decline in circulating androgens 23 . Inconsistence of our finding of no correlation between hyperinsulinemia and hyperandrogenemia with some studies2,18, may be due to difference of diagnostic criteria used for subject selection. We also didn't find significant correlation between fasting plasma glucose and insulin. This might be related to a balance of hyperinsulinemia with a rising plasma glucose that could lead to increased severity of IR years after initial developments of biochemical abnormality. There was also no significant correlation between $\mathrm{S}$. free testosterone and fasting plasma glucose. This finding was consistent with a similar study25. Probably testosterone has no significant influence on glucose metabolism.
In conclusion we found hyperinsulinemia and hyperandrogen emia in PCOS patients, but correlation between them was not proved. There was a limitation of our study of smaller number of control subjects. So, further study including larger sample sizes categorizing study subjects using different diagnostic criteria is recommended.

\section{References}

1. Knochenhauer ES, Key $T J, K$ ahsar-M illaer $M$, Waggoner $W$, Boots $L R$, Azziz R.Prevalence of the polycystic ovary syndrome in unselected black and white women of south-eastern U nited States: a prospective study. J Clin Endocrinol Metab 1998; 83: 3078-3082.

2. Burghen GA, Givens JR, Kitabchi AE. Correlation of hyperandrogenism and hyperinsulinemia in polycystic ovarian disease. J Clin Endocrinol M etab 1980; 50: 113-116.

3. Dunaif A. Insulin resistance and the polycystic ovary syndrome:mechanism and implications for pathogenesis. Endocr Rev 1997; 18: 774-800.

4. Pasquali $R$, Antenucci $D, C$ assimirri $F$, Venturoli $S$, Paradisi R, Fabbri R, Balestra $V$ et al. Clinical and hormonal characteristics of obese amenorrheic hyperandrogenic women before and after weight loss. J Clin Endocrinol M etab 1989; 68: 173-179.

5. Konar H(ed). DC Dutta Text book of gynaecology. 3rd edition. Kolkata(India). New Central Book A gency(P) Ltd. 2001: 422.

6. Taylor AE.Polycystic ovary syndrome. Endocrinol M etab Clin N A m 1998 a; 27: 877-902.

7. Plymate $S R, M$ atej $L A$, Jones $R E$, Friedl $K E$. Inhibition of sex hormone binding globulin production in the human hepatoma (Hep G2) cell line by insulin and prolactin. J Clin Endocrinol Metab 1988. 67: 460-464.

8. M artikinen $H$, Salmela $P$, Nuojua HS, Perala J, Leinonen $S$, Knip $M$, Ruokonen $A$. Adrenal steroiogenesisis related to insulin in hyperandrogenic women. Fertil Steril 1996; 66: 564-570.

9. Nestler JE. Barlascini CO, M att DW, Steingold KA,PLymate SR, Clore JN et al. Suppression of serum insulin by diazoxide reduces serum testosterone levels in obese women with polycystic ovary syndrome. J Clin Endocrinol M etab 1989; 68: 1027-1032.

10. M orin-Papunen LC, M artikainen HK, K oivunen 
Insulin and A ndrogen Status in PCOS

RM, Ruoken A. Metformin therapy improves the menstrual pattern with minimal endocrine and metabolic effect in women with polycystic ovary syndrome. Fertil Steril 1998; 69: 691-696.

11. M orin-Papunen LC, V auhkonen I, Koivunen RM, Ruoken A, Tapanainamen JS. Insulin sensitivity, insulin secretion and metabolic and hormonal parameters in healthy women and women with polycystic ovary syndrome. Hum Reprod 2000a; 15: 1266-1274

12. D unaif A, Graf $M$, M andeli J, L aumas V, D obrjansky A. Characterization of groups of hyperandrogenic women with acanthosis nigricans, impaired glucose tolerance and / or hyperinsulin regismia. J Clin Endocrinol M etab 1987. 65:499-507.

13. Dunaif A, Segal KR, Futterweit W, Dobrjansky A. Profound peripheral insulinrestance, independent of obesity, in polycystic ovary syndrome. Diabetes 1989; 38: 1165-1174.

14. Richardson MR. Current perspective in polycystic ovary syndrome.Am Fam Physician 2003; 68: 697704.

15. Holte J, Bergh T, Berne C, Wide L, Lithell $H$. Enhanced early insulin response to glucose in relation to insulin resistance in women with polycystic ovary syndrome and normal glucose tolerance. J Clin Endocrinol M etab 1994a; 78: 10521058.

16. Ducluzeau PH, Cousin P, Malvosin E, Bornet $H$, Vidal $H$, Laville $M$, Pugeat. Glucose to insulin ratio rather than sex hormone binding globulin \& adiponectin levels is the best predictor of insulin resistance in nonobese women with polycystic ovary syndrome. J Clin Endocrinol M etab 2003; 88: 3626-3631.

17. Anttila L, Ding $Y Q$, Ruutianen $K$, Erkkola $R$, Irjala K, Huhtaniemi I. Clinical features and circulating gonadotrophin, insulin and androgen interaction in women with polycystic disease. Fertil Steril 1991; 55: 1057-1061.
18. Chang RJ, Nakumura RM, Judd HL, Kaplan SA. Insulin resistance in non-obese patients with polycystic ovarian disease. J Clin Endocrinol M etab 1983; 57: 356-369.

19. L argo RS, Finegood D, Dunaif A. A fasting glucose to insulin ratio is a useful measure of insulin sensitivity in women with polycystic ovary syndrome. J Clin Endocrinol Metab 1998; 83: 26942698.

20. Dunaif A, Finegood DT. Beta cell dysfunction independent of obesity and glucose intolerance in the polycystic ovary syndrome. J Clin Endocrinol M etab 1996; 81: 942-947.

21. Toscano V, Bianchi P, Balduccio R, Guglielmi R, $M$ augiantini $A$, Lubrano $C$, et al. Lack of linear relationship between hyperinsulinemia and hyperandrogenism. Clin Endocrinol(Oxf) 1992; 36: 197-202.

22. Vidal-Puig A, M unoz-Torres $M$, Jodar-GimenoE, Garcia-Calvente C, Lardelli P, Ruiz-Requena ME et al. Hyperinsulinemia in polycystic ovary syndrome: relationship to clinical and hormonal factors. Clin Inves 1994; 72: 853-857.

23. Poretsky L, Cataldo NA, Rosenwaks Z, Giudice $L C$. The insulin related ovarian regulatory system in health and disease. Endocrinol Rev 1999; 20: 535 582.

24. A nttila $L$, Koskinen $P$, Jaatinen TA, Erkkola R, Irjala $K$, Ruutiainen $K$. Insulin hypersecretion together with high luteinizing hormone concentration augments androgen secretion in oral glucose tolerance test in women with polycystic ovarian disease. Hum Reprod 1993; 9: 1179-1183.

25. Titinem A, Pekonen $F$, Sueinman UH, Laatikainen T. Plasma androgen and oestradiol during oral glucose tolerance test in patients with polycystic ovaries. Human Reprod 1998; 5: 242-245. 